\title{
Design and Optimization of Processing Conditions for a Recent Quenched and Partitioned Steel
}

Eman Hassan El-Shenawy, Hoda Nasr El-Din Hedia, Mai Mohamed Kama-El-Din and Hoda Refaiy Badwy

\author{
Eman Hassan El-Shenawy. Metal Forming Department, Central Metallurgical R\& D institute (CMRDI), Cairo, Egypt \\ Hoda Nasr El-Din Hedia. Metal Forming Department, Central Metallurgical R\& D institute (CMRDI), Cairo, Egypt \\ Mai Mohamed Kama-El-Din. Chemical Engineering Department, Faculty of Engineering, Cairo University, Cairo, Egypt \\ Hoda Refaiy Badwy. Metal Forming Department, Central Metallurgical R\& D institute (CMRDI), Cairo, Egypt. \\ Corresponding author: Hoda Refaiy, E-mail address: eng_huda_refaiy@yahoo.com
}

\begin{abstract}
Q\&P steels as a "Third Generation" of (AHSS) exhibit excellent tensile properties, which enable producing lightweight sections for the automotive industry and at the same time keep safety requirements. This research aims to predict the proper processing conditions for developing ultra-high-strength Q\&P steel with a novel chemical composition of $0.37 \mathrm{C}-3.65 \mathrm{Mn}-0.65 \mathrm{Si}-0.87 \mathrm{Al}-1.5 \mathrm{Ni}-0.05 \mathrm{P}$, wt. \%. To design and optimize proper heat treatment conditions, the phase diagram, ССT curve, and critical temperatures of these alloys were first implemented using THERMO-CALC and JMATE PRO software and Gleeble 3500 machine. The heat treatment process included full austenitization, then quenching at $120^{\circ} \mathrm{C}$ followed by partitioning at $450^{\circ} \mathrm{C}$ for different times. The tensile properties, microstructure, and retained austenite volume fraction of heattreated steel was studied at room temperature by tensile testing machine, optical microscope, and XRD. The finding summarized that partitioning of this steel for $100 \mathrm{~s}$ during processing had developed Q\&P steel with ultra-high-strength of $1104 \mathrm{MPa}$ with maximum total elongation and strength elongation balance $8.1 \%$ and $8932 \mathrm{MPa} \%$, respectively. The optical micrograph showed that heat-treated specimens at different partitioning times have had a microstructure of tempered martensite, carbide free bainite, and retained austenite. Besides, the retained austenite volume fraction has decreased with increasing partitioning time, which may be due to carbide precipitation during partitioning.
\end{abstract}

Keywords. Automotive Steel, Advanced High Strength Steel, Quenching And Partitioning, Retained Austenite, Ultra-high-strength Steel

\section{Introduction}

Researchers are working hard to find solutions for reducing vehicle sectors' emissions, contributing to a high percentage of greenhouse gases (GHG) and possibilities for decreasing energy consumption. This can be achieved by developing new advanced material with excellent mechanical properties that enable producing lightweight sections and, at the same time, keep passengers safe. Advanced high strength steels (AHSS) are outstanding material that fulfills requirements of environment and energy [1]. AHSSs have a unique microstructure that promotes enhancing mechanical properties. These steels' microstructures consist of ultra-fine phases like martensite and bainite, with retained austenite formed in non-equilibrium conditions [2]. AHSSs include three generations with different range of strength and elongations, which are a promising lightweight material in the 21st century. The first generation AHSSs grade such as dual-phase (DP) steel and transformation-induced plasticity (TRIP) steel has higher strength and better elongation with low cost compared to conventional high strength steels [2][3]. The second-generation AHSS has outstanding strength, strength-elongation balance, and formability compared to first generation. This generation's problem is the high content of alloying elements, which increases their alloys' cost. Therefore, the third generation of AHSSs have developed to overcome the high cost of the second generation and simultaneously fulfill high mechanical properties compared to the first generation [2][3].

Recently, the scientific and industrial communities are paying attention to developing Q\&P steels as a "Third Generation" (AHSS) that was first processed by J. Speer et al. 2003 [4]. The tensile properties of Q\&P steel can surpass 
or equal that of TRIP, conventional dual-phase, and martensitic steels [4]. Furthermore, it has a high work-hardening rate and formability, which promote it to be used for structural and safety sections in automotive applications [4]. This steel's high mechanical properties result from its multiphase microstructure, which mainly consists of a martensite matrix and retained austenite films [5]. The presence of the martensite phase in steel microstructure enhances the yield strength while the ductility and work hardening are improved due to the TRIP effect of retained austenite [6].

The main factors that affect the microstructure of Q\&P steels are the proper choice of alloy composition and processing conditions, which support carbon partitioning from martensite to austenite and retard the formation of other phases such as bainite, ferrite, and carbides after quenching to room temperature in the final stage [7][8]. The alloy design of Q\&P steel was first based on commercial TRIP steels' chemical composition, where conventional TRIP steel compositions are usually based on the original 0.12-0.55 wt.\% C, 0.2-2.5 wt.\% Mn, and 0.4-1.8 wt.\% Si concept [9][10]. N. Maheswari et al. reported that the addition of (C, Mn, Si, Al) to the composition of Q\&P steel alloy had reinforced the formation of prevalent martensite lathes and inter-lathes austenite in the final microstructure, which has positively affected the mechanical properties of these steels [11]. According to a previous study, increasing carbon content from $0.3 \%$ to $0.4 \%$ in alloyed steel with $1.5 \% \mathrm{Mn}$ has increased the retained austenite volume fraction. Consequently, the ultimate tensile strength and elongations are enhanced from $1490 \mathrm{MPa}$ to $1865 \mathrm{MPa}$ and $12 \%$ to $15 \%$, respectively [12]. E. J. Seo. et al. (2015) applied the Q\&P process to medium Mn steel alloy with a chemical composition of Fe-0.21C-4.0Mn-1.6Si-1.0 Cr (in wt. pct). The findings from this study demonstrated that a high volume fraction of retained austenite with enriched carbon and a microstructure of retained austenite islands in low-C martensite matrix was achieved. This medium Mn steel alloy also exhibited an outstanding strength-elongation balance of about 25,400 MPa \% [13]. Besides, Nickel's presence in the Fe-Mn-Si-C Q\&P steel composition enhances stabilization of retained austenite against strain-induced martensitic transformation during deformation [14].

The Q\&P heat treatment process involves various stages of initial partial or full austenitization at high temperature, then quenching to a pre-determined temperature between Ms and Mf to acquire a proper percentage of primary martensite and remaining austenite, followed by partitioning at a higher temperature [15][16]. During the quenching stage, both martensite and untransformed retained austenite phases are firstly obtained. The subsequent partitioning is commonly carried out at a temperature slightly higher than the quenching temperature to stabilize the retained austenite at lower temperatures [17][18].

This research aims to determine and optimize convenient heat treatment processing conditions for developing Q\&P steel with a novel chemical composition of $0.37 \mathrm{C}-3.65 \mathrm{Mn}-0.65 \mathrm{Si}-0.87 \mathrm{Al}-1.5 \mathrm{Ni}-0.05 \mathrm{P}$, wt. \%. The phase diagram and critical transformation temperature have been implemented first using the thermo-calc CALPHED method and the Gleeble 3500 machine. The effect of some heat treatment conditions on the tensile properties and microstructure of this Q\&P steel alloy has been included.

\section{Experimental work}

It is well known that the composition and processing conditions promote developing Q\&P steel alloy with excellent mechanical properties. The chemical composition of the investigated steel alloy is shown in Table 1. This composition's strategy is based on choosing the proper alloying elements that retard carbide precipitation and allow diffusion of carbon from Martensite to untransformed austenite during partitioning. This steel alloy was produced in an induction furnace by sand casting process; then, the as-cast alloy was machined into sections with $200 \mathrm{~mm} \times 60 \mathrm{~mm} \times 40 \mathrm{~mm}$ and homogenized at $1250^{\circ} \mathrm{C}$ for $2 \mathrm{hrs}$. Before the hot deformation and heat treatment processes, the phase diagram and CCT curve of the alloy were simulated using thermo-calc (CALPHAD Method) and J-Mate pro software (see figures 1 and 2). The critical transformation temperatures were also identified by dilatation test, which was done by using a Gleeble 3500 machine. Figure 3 demonstrates the alloy's dilatation curve where AC1, AC3, and MS are $720^{\circ} \mathrm{C}, 810^{\circ} \mathrm{C}$, and $260^{\circ} \mathrm{C}$, respectively. The homogenized sections were initially hot forged into plates with a thickness of $7 \mathrm{~mm}$, then 
hot rolled into sheets with a thickness of $1.8 \mathrm{~mm}$. The tensile specimens were machined from the hot-rolled sheet based on the ASTM E8 standard.

Table 1: The chemical composition of the studied alloy.

\begin{tabular}{lllllll}
\hline C & Mn & Si & Al & Ni & P & S \\
\hline 0.37 & 3.65 & 0.65 & 0.87 & 1.5 & 0.05 & 0.015 \\
\hline
\end{tabular}

Figure 4 demonstrates the heat treatment process of the specimens, which included full austenitization at $900^{\circ} \mathrm{C}$ for 10 mins followed by rapid quenching into an oil bath furnace at $120^{\circ} \mathrm{C}$, which is below the martensite start temperature, then rapidly transferred into another salt bath at $450^{\circ} \mathrm{C}$ (higher than $\mathrm{M}_{\mathrm{S}}$ ) for a different time before quenching to room temperature. The quenching temperature was determined depending on the Koistinen-Marburger formula (Equation 1), where about $75 \%$ of primary martensite was expected to form at this temperature during the quenching stage. A tension test of heat-treated specimens was carried out at room temperature using LFM- L 20 KN machine. Before microstructure investigation, the specimens were metallography prepared by abrasion of the specimens' surface with grit papers until scratches and damage were removed then polishing with alumina past. The developed Q\&P specimens were etched by using $10 \%$ Sodium Meta Bi-Sulphate for $30 \mathrm{~s}$ then they were studied by optical microscope where the retained austenite appears white, and martensite appears black. The volume fraction of retained austenite and its carbon content was estimated using $\mathrm{Cu}$ target XRD at $45 \mathrm{kV}$ and $40 \mathrm{~mA}$.

$$
f_{M}^{T q}=1-e^{-1.1 \times 10^{-2}\left(M_{s}-T_{q}\right)}
$$

Where $\mathrm{f}_{\mathrm{M}}, \mathrm{M}_{\mathrm{S}}, \mathrm{T}_{\mathrm{q}}$ are volume fraction of primary martensite, martensite start temperature, and quench temperature, respectively. 


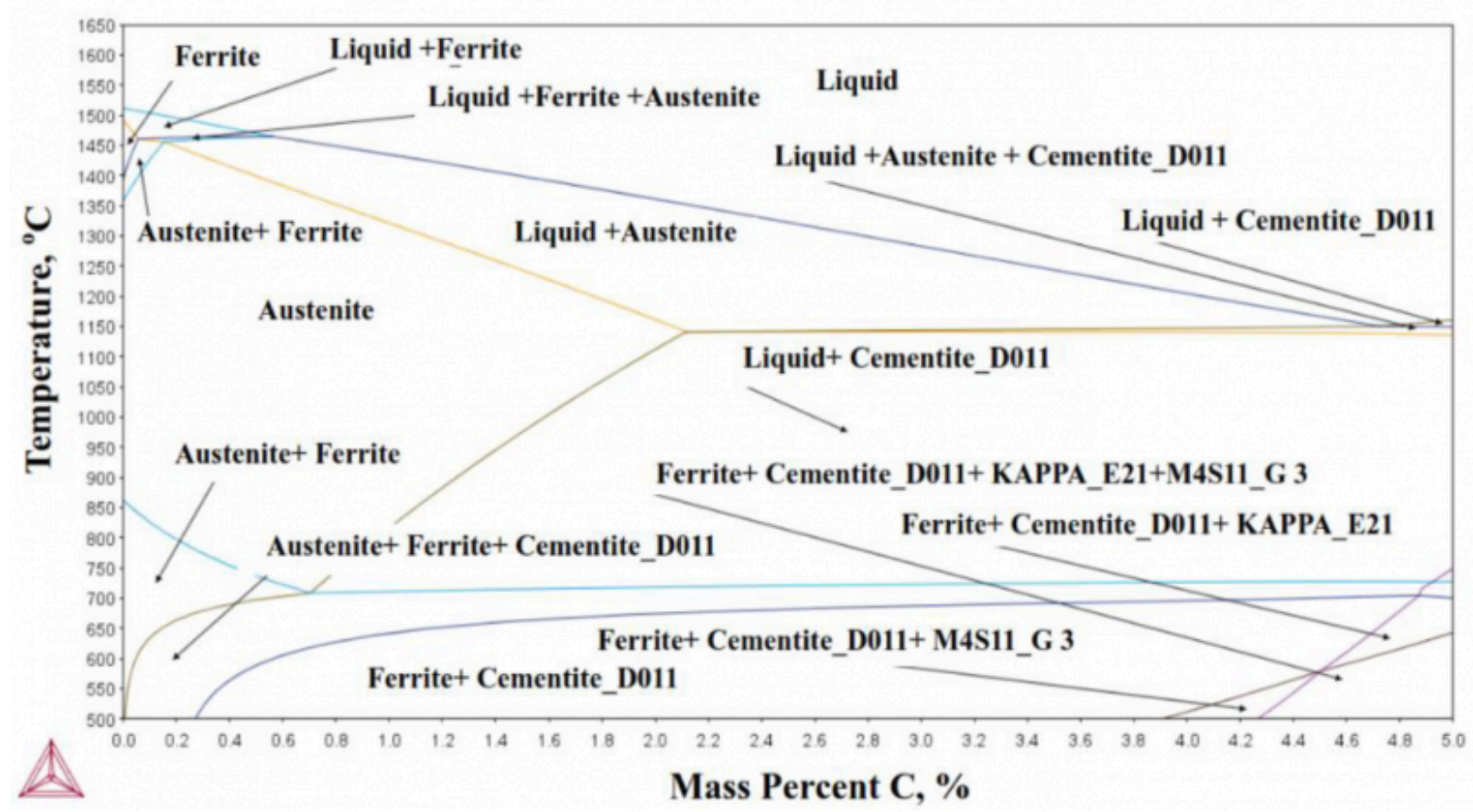

Fig. 1. Simulated Iron-Carbon phase diagram of the studied steel alloy

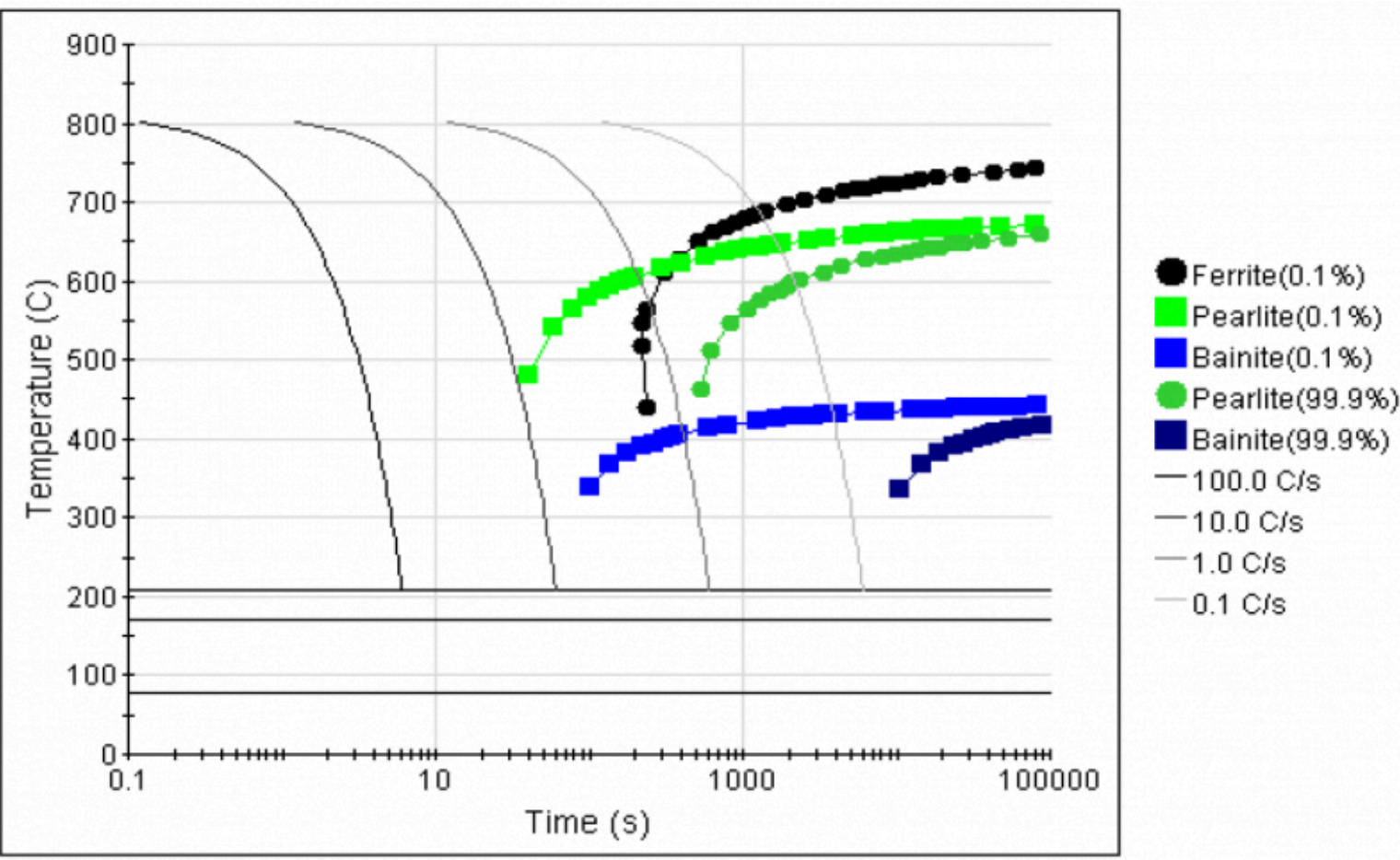

Fig. 2. predicted CCT curve of the studied alloy 


\section{Results and Discussion}

\subsection{Microstructure investigation}

Figure 5 demonstrates the optical micrographs of developed Q\&P steel partitioned for different times of $20 \mathrm{~s}$, 60 s, $100 \mathrm{~s}, 140 \mathrm{~s}$, and $180 \mathrm{~s}$. It is obvious that all investigated specimens' microstructure has composed of tempered martensite (black area), retained austenite ( $\gamma \mathrm{r}$ ) (white area), and a percent of carbide-free bainite ( $\alpha \mathrm{b})$ (a gray area). The optical micrographs also indicated that increasing partitioning time from the $20 \mathrm{~s}$ to $100 \mathrm{~s}$ displayed a small change in the morphology and size of fine coexisted phases. In comparison, the long partitioning time of $140 \mathrm{~s}$ and $180 \mathrm{~s}$ resulted in increasing retained austenite size (see figure 5 e and $\mathrm{f}$ ). The formation of carbide-free bainite phase in this microstructure may be attributed to the slow decomposition of $\varepsilon$ carbide existed in the martensite during the partitioning stage, leading to incomplete carbon diffusion into untransformed austenite. As a result, a small fraction of bainite or bainitic ferrite is created in the final microstructure with retained austenite and tempered martensite [19]. The optical micrographs of this investigated Q\&P steel demonstrated a general overview of the microstructure, but scanning electron microscopy will be performed for more identification of phases.

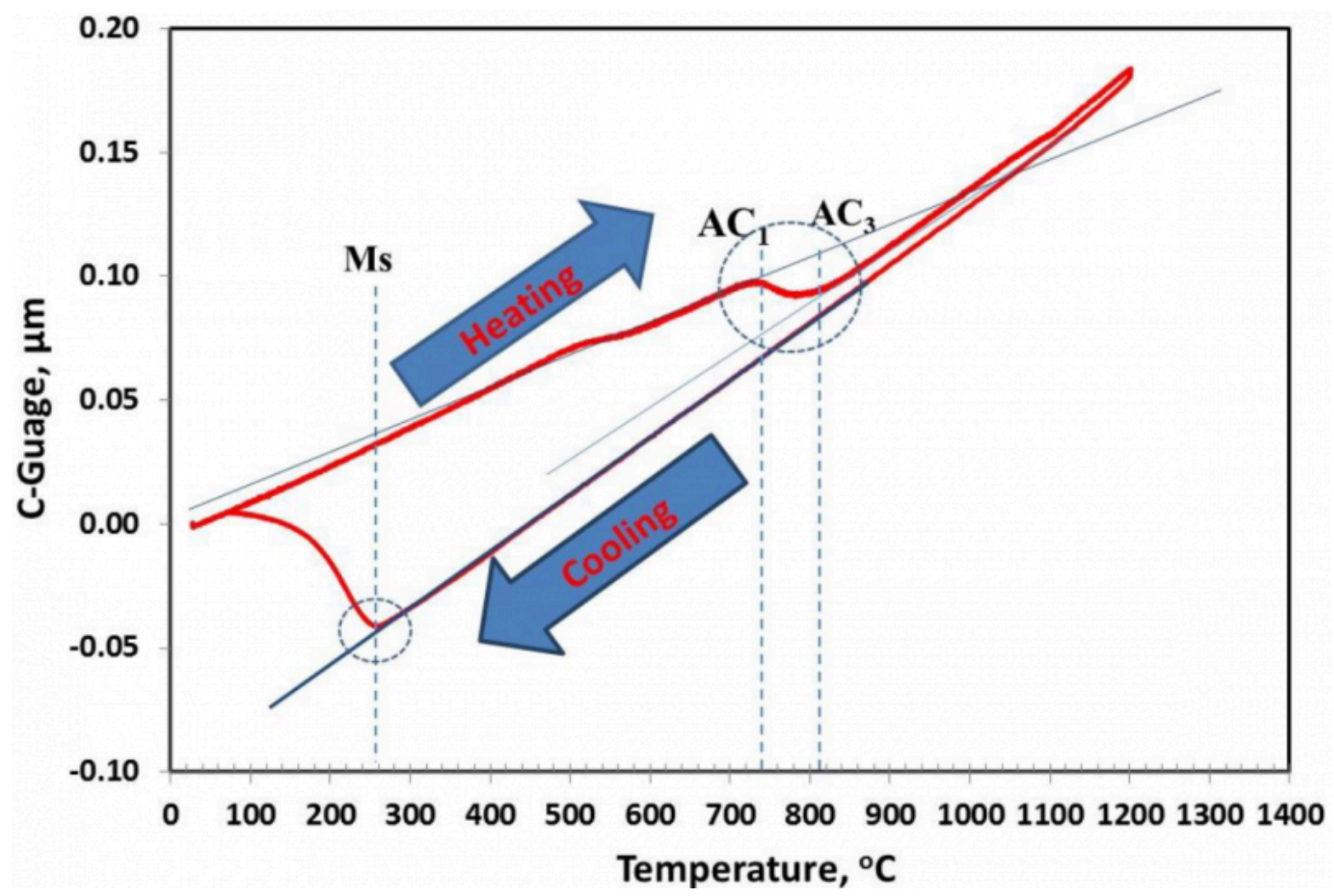

Fig.3. dilatation curve of the investigated steel alloy 


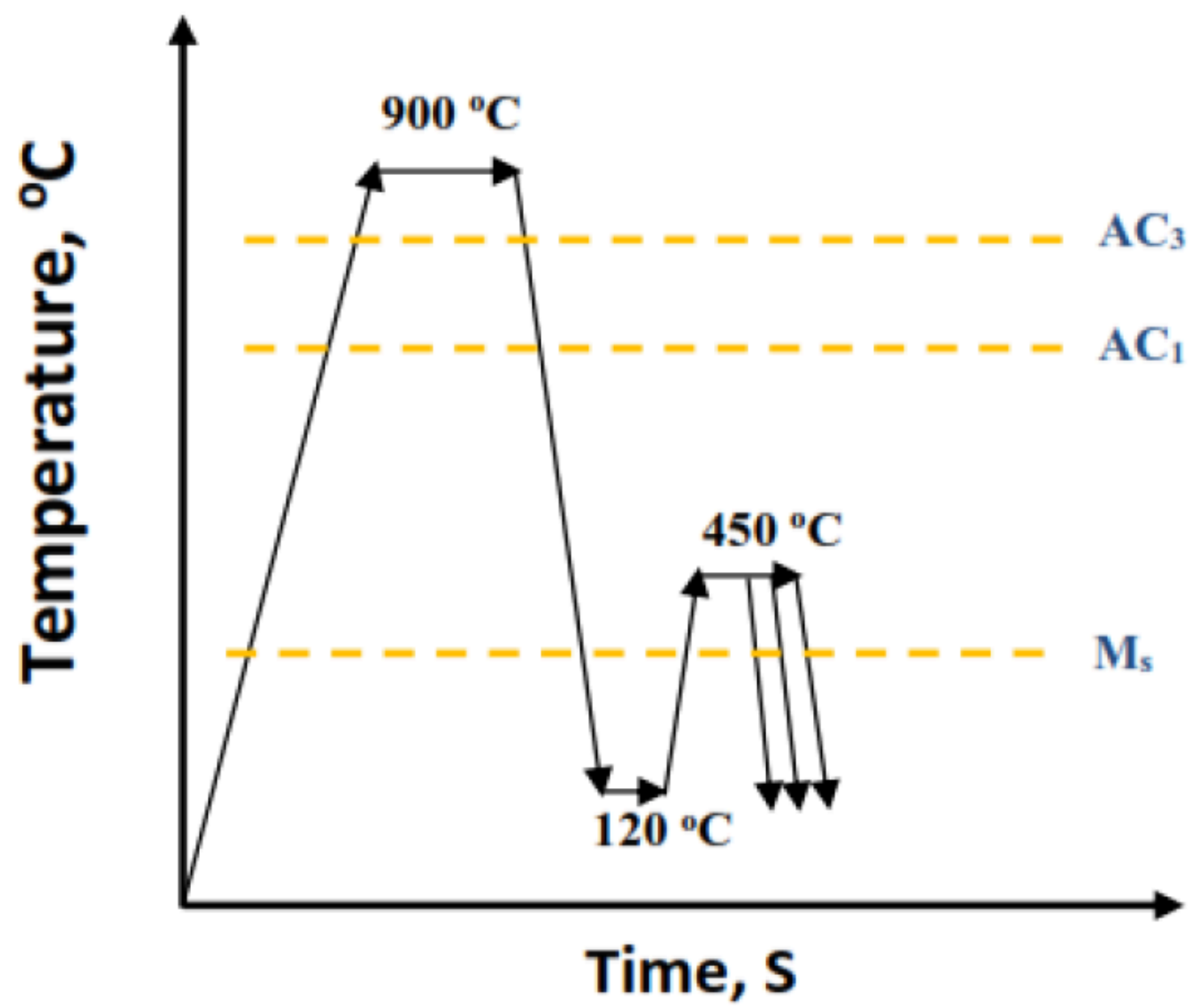

Fig. 4. Heat treatment strategy for studied steel alloy specimens

\subsection{Retained austenite characteristics}

Figures 6 shows the peak intensity for austenite and other phases in developed Q\&P steel partitioned at different times (20 s up to $180 \mathrm{~s}$ ). XRD patterns confirm that the FCC structure phase is present. Table 2 indicates the variation of retained austenite volume fraction $(\mathrm{V} \gamma)$ with partitioning time $(\mathrm{Pt})$ of studied Q\&P steel. It is noticed that the increment of partitioning time resulted in a decline of retained austenite volume fraction from $7 \%$ for $20 \mathrm{~s}$ to $3 \%$ for $180 \mathrm{~s}$. The decrease of retained austenite fraction at long partitioning time may be attributed to the formation of carbides. J. Speer et al. 2003 demonstrated that stabilization of retained austenite is accomplished by diffusion of carbon during the partitioning step from the supersaturated martensite into untransformed austenite [4]. Some studies referred that the partitioning of carbon is not completed due to segregation or clustering of carbon, or formation of carbides. The precipitation of carbides results in the consumption of available carbon in the martensite, which diffuses to untransformed austenite during partitioning [20-23]. The formation of bainite during partitioning also may play a role in reducing the volume fraction of austenite for a long partitioning time [24]. A recent study used transmission electron microscopy (TEM) and atom probe tomography (APT) to investigate the kinetics of transformation and carbide formation at high partitioning temperatures of $360^{\circ} \mathrm{C}$ or $420^{\circ} \mathrm{C}$ for $300 \mathrm{~s}$ during the processing of Q\&P steel. The results indicated that the austenite volume fraction has decreased from $14 \%$ to $7 \%$ during partition, resulting from bainite formation. The martensite tempering has led to the formation of $\theta$-carbide, and $\chi$-carbide has existed in austenite. The APT measurements revealed that carbide precipitation resulted from austenite decomposition [25]. The effect of partitioning conditions during processing on the microstructure of 0.38 C-1.54 Mn-1.48 Si wt. \% Q\&P steel has 
been studied by using Mössbauer spectroscopy and transmission electron microscopy. This research concluded that partitioning at $450^{\circ} \mathrm{C}$ for short partitioning times has decreased carbide formation and carbon contents in martensite and has augmented the amount of retained austenite. On the other hand, longer partitioning times have promoted austenite decomposition, which forms cementite in martensite [26]. S. Ebner et al. 2020 also investigated carbide formation during the processing of Q\&P steel with two different chemical compositions by in-situ high-energy X-ray diffraction. The author pointed that partial decomposition of austenite and martensite tempering leads to carbide precipitation [25].

Table 2: volume fraction of retained austenite of this Q\&P steel partitioned at different times

\begin{tabular}{lllllll}
\hline Pt (s) & 20 & 40 & 60 & 100 & 140 & 180 \\
\hline $\mathrm{V} \gamma, \%$ & 7 & 5 & 4 & 5 & 4 & 3 \\
\hline
\end{tabular}

\subsection{Tensile properties}

Figure 7 demonstrates the engineering stress-strain curves of heat-treated specimens. As shown in this figure, all the specimens exhibited continuous yielding behavior. This behavior may be attributed to some nitride-forming elements such as $\mathrm{Al}$ and $\mathrm{Si}$, which decrease carbon and nitrogen interstitial atoms that impede dislocation movement [27]. Consequently, the mobile dislocation density is increased [28]. Table 3 summarizes the tensile properties of developed Q\&P steel. It is clear that the tensile strength does not depend on partitioning time until $60 \mathrm{~s}$ then it has decreased from $1157 \mathrm{MPa}$ at $60 \mathrm{~s}$ to $1026.8 \mathrm{MPa}$ at $180 \mathrm{~s}$ while the total elongation (TEL) and strength elongation balance (UTS*TEL) have improved with increasing partitioning time to $100 \mathrm{~s}$ then they have decreased. The developed Q\&P steel has exhibited maximum elongation and strength elongation balance of about $8.1 \%$ and $8932 \mathrm{MPa} \%$ with an ultimate tensile strength value of $1104 \mathrm{MPa}$ when partitioned for $100 \mathrm{~s}$.

It has formerly been reported that the high strength of Q\&P steel is due to the existence of a high amount of tempered martensite. In contrast, a high amount of meta-stable retained austenite enhances the ductility by the related transformation induced plasticity (TRIP) effect [24]. The decrease of tensile strength at long partitioning time is due to softening the primary martensite phase formed during the first quenching [29]. The low elongation of this Q\&P steel partitioned at $20 \mathrm{~s}$ with the highest volume fraction of retained austenite may be due to the presence of a high amount of un-tempered primary martensite. The decrease of retained austenite volume fraction, which has a larger grain size (Figure 5 e), leads to a reduction of total elongation at long partitioning time. 

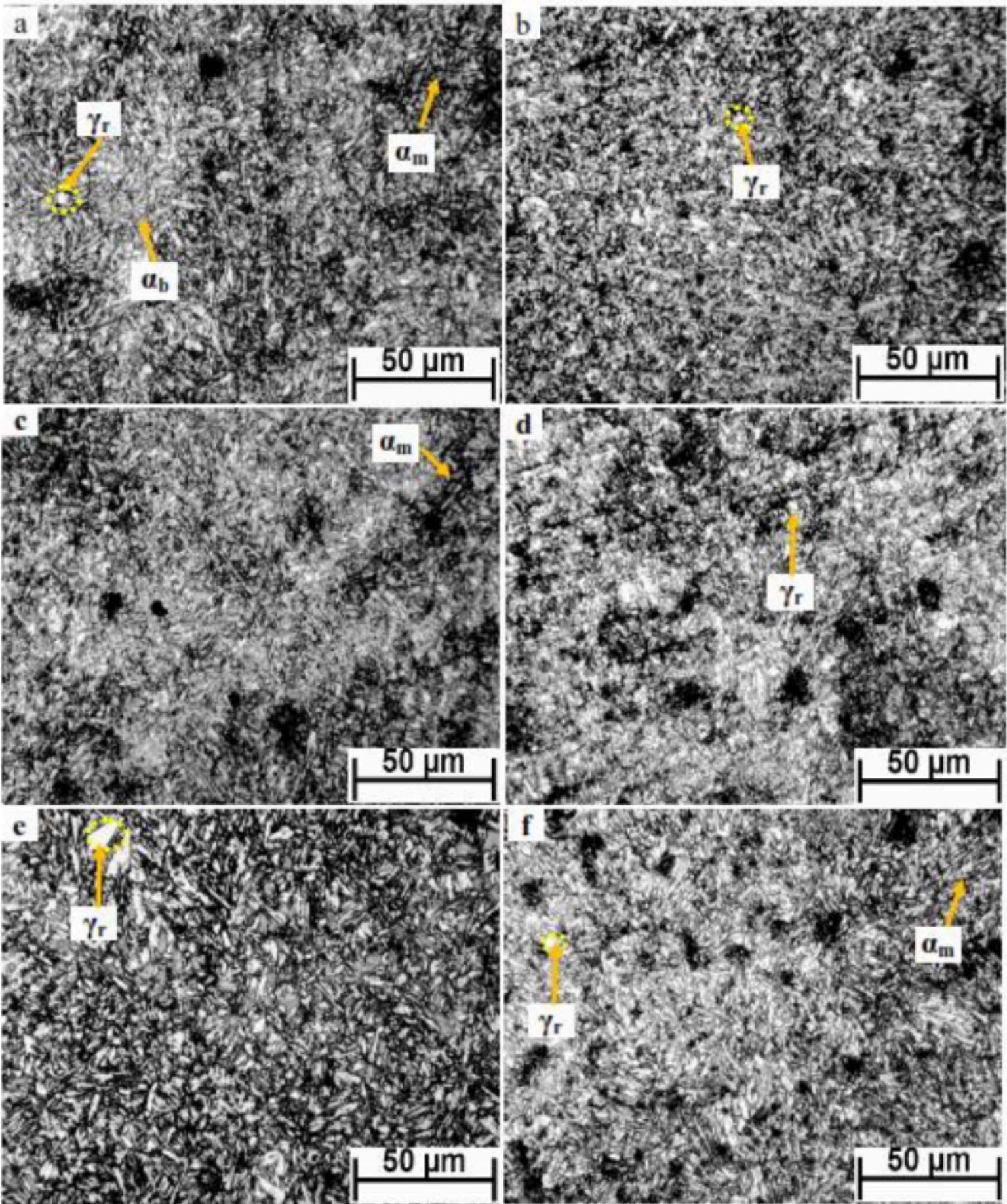

Fig. 5. optical micrographs of investigated Q\&P steel partitioned at $450^{\circ} \mathrm{C}$ for (a) $20 \mathrm{~s}$, (b) $40 \mathrm{~s}$, (c) $60 \mathrm{~s}$, (d) $100 \mathrm{~s},(\mathrm{e}) 140$ s, and (f)180 s 


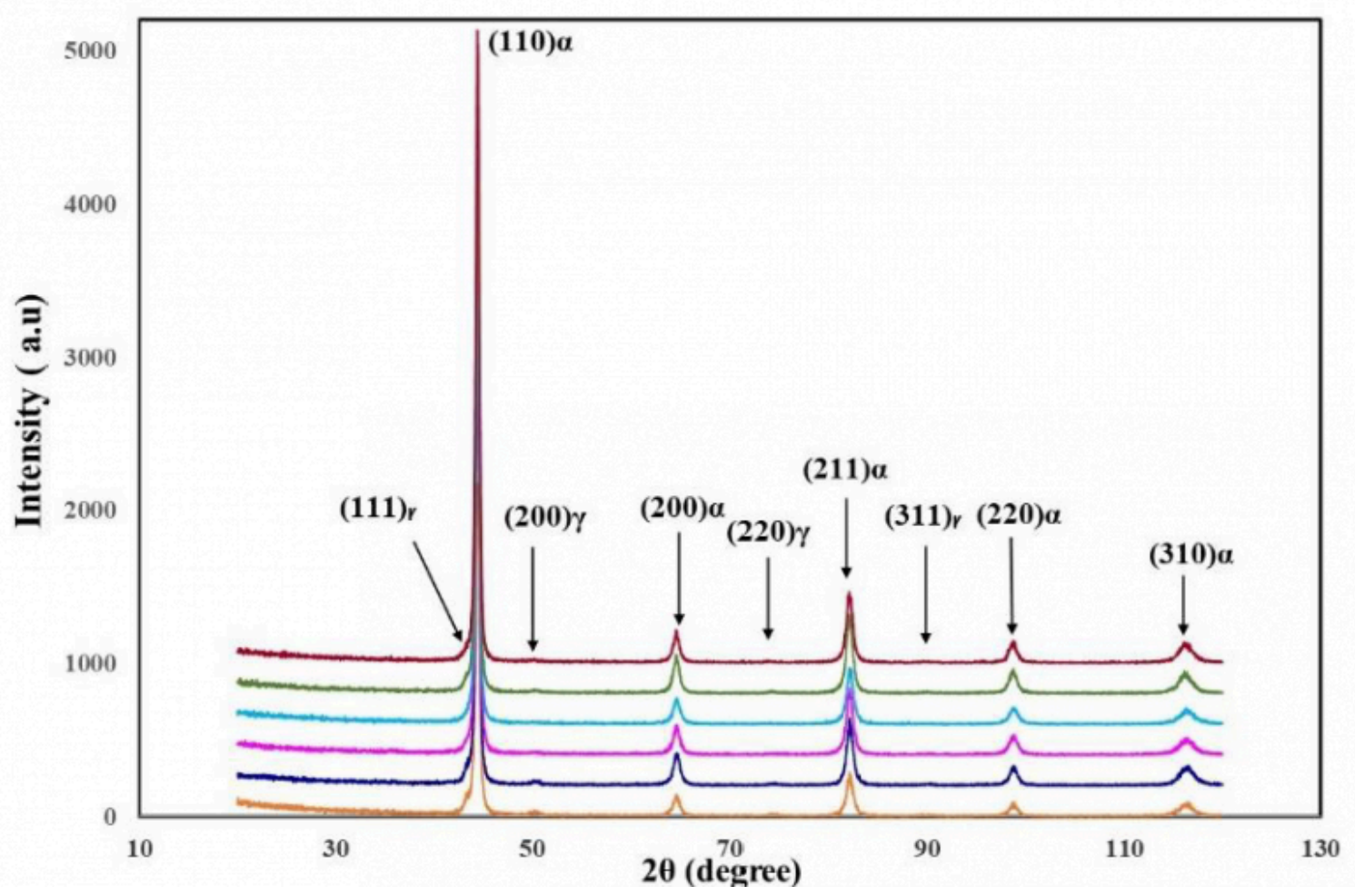

Fig. 6. XRD diffraction peaks of developed Q\&P steel partitioned at $450^{\circ} \mathrm{C}$ for different times (20 s up to $\left.100 \mathrm{~s}\right)$.

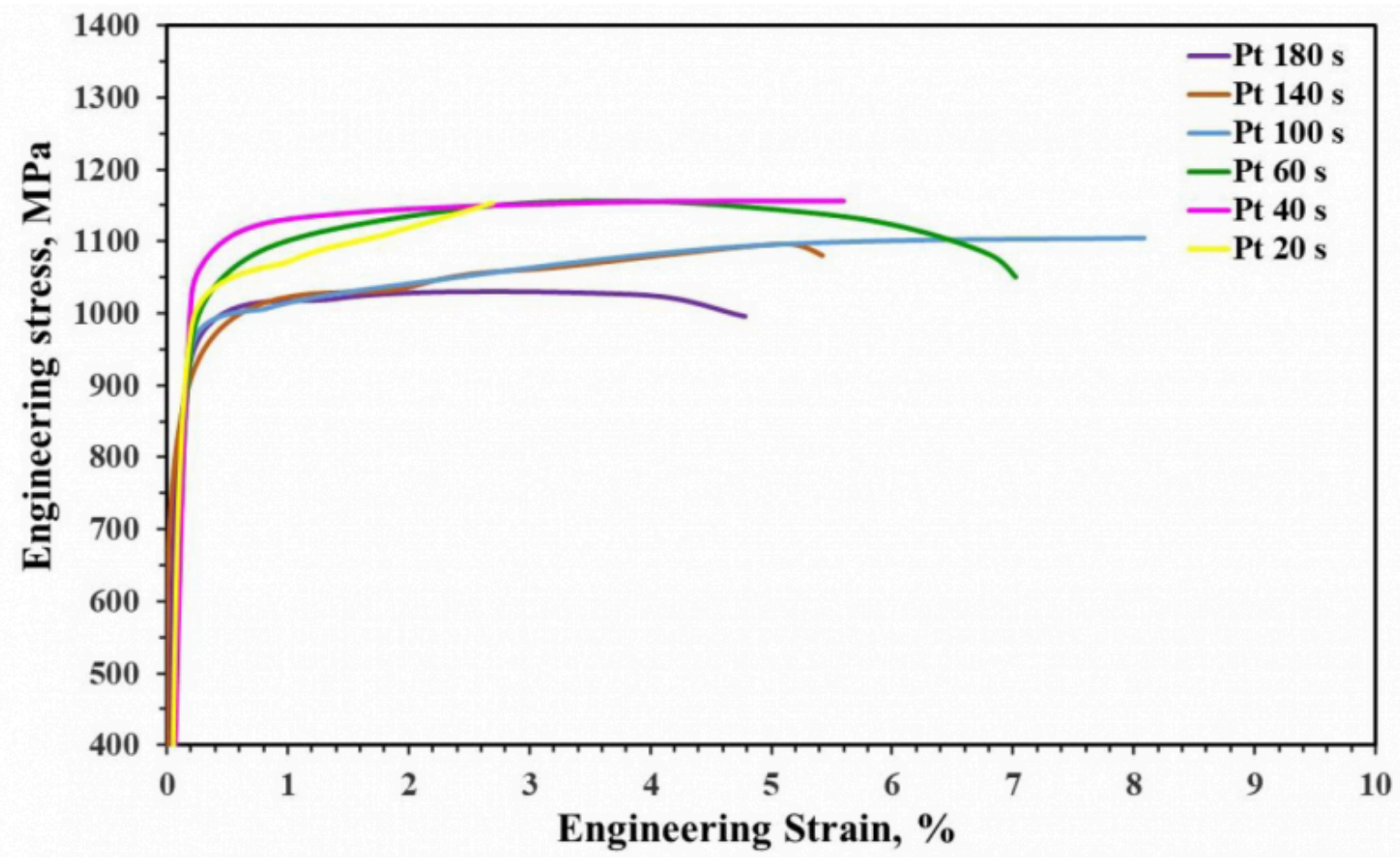

Fig. 7. Engineering stress strain curves of developed Q\&P steel partitioned at $450^{\circ} \mathrm{C}$ for different times (from $20 \mathrm{~s}$ up to 
Design and Optimization of Processing Conditions for a Recent Quenched and Partitioned ...

$180 \mathrm{~s})$

Table 3: Tensile properties of developed Q\&P steel partitioned at $450^{\circ} \mathrm{C}$ for different times.

\begin{tabular}{llllllc}
\hline Pt (s) & 20 & 40 & 60 & 100 & 140 & 180 \\
\hline UTS, MPa & 1153.2 & 1155.5 & 1157.0 & 1104.2 & 1096.1 & 1026.8 \\
\hline TEl, \% & 2.7 & 5.6 & 7.0 & 8.1 & 5.7 & 4.8 \\
\hline UTS*El, MPa. \% & 3079.0 & 6436.1 & 8122.1 & 8932.7 & 6214.9 & 4959.3 \\
\hline
\end{tabular}

\section{Conclusion}

In this study, the phase diagram, CCT curve, and dilatation test of $0.37 \mathrm{C}-3.65 \mathrm{Mn}-0.65 \mathrm{Si}-0.87 \mathrm{Al}-1.5 \mathrm{Ni}-0.05 \mathrm{P}, \mathrm{Wt}$. $\%$ steel alloy were performed in order to design heat treatment condition for developing a novel Q\&P steel. The heat treatment process comprised quenching at $120^{\circ} \mathrm{C}$ then partitioning at $450^{\circ} \mathrm{C}$ for different times (20 s up to $\left.180 \mathrm{~s}\right)$. The results showed that:

- The heat treatment process of studied Q\&P steel partitioned at different times resulted in the formation of tempered martensite retained austenite and carbide free bainite in the microstructure. At partitioning time from $20 \mathrm{~s}$ to $100 \mathrm{~s}$, a slight difference in the microstructure has observed while long partitioning time has displayed an increase in austenite grain size.

- The volume fraction of retained austenite has decreased with increasing partitioning time, which may be due to carbide precipitation during partitioning.

- The decrease in retained austenite fraction at long partitioning is accompanied by a decline in total elongation and strength elongation balance. In contrast, the ultimate tensile strength is reduced due to the tempering of primary martensite. The partitioning time of $100 \mathrm{~s}$ has resulted in a maximum elongation and strength elongation balance of $8.1 \%$ and $8932 \mathrm{MPa} \%$ with an ultimate tensile strength of $1104 \mathrm{MPa}$.

\section{Bibliography}

[1] D. Matlock, J. Speer, E. De Moor,P. Gibbs. Recent developments in advanced high strength sheet steels for automotive applications: an overview. 2012, 15, no. 1, 1-12.

[2] J. Zhao, Z. Jiang. Thermomechanical processing of advanced high strength steels," Progress in Materials Science. Elsevier Ltd, 2018, 94, 174-242, DOI: 10.1016/j.pmatsci.2018.01.006.

[3] Advanced high-strength steels application guidelines, 2016, http://www.WorldAutoSteel.com

[4] J. Speer, D. K. Matlock, B.C. De Cooman, J.G. Schroth. Carbon partitioning into austenite after martensite transformation. Acta Mater,2003, 51, no. 9, 2611-2622, DOI: 10.1016/S1359-6454(03)00059-4.

[5] L. Wang, J. Speer. Quenching and partitioning steel heat treatment. Metallogr. Microstruct. Anal.,2013, 2, no. 4, 268281, DOI: $10.1007 / \mathrm{s} 13632-013-0082-8$.

[6] C.B. Finfrock. A. J. Clarke, G.A. Thomas, K. D. Clarke. Austenite stability and strain hardening in C-Mn-Si quenching 
and partitioning steels. Metall. Mater. Trans. A Phys. Metall. Mater. Sci.,2020, 51, no. 5, 2025-2034, DOI: 10.1007/ s11661-020-05666-8.

[7] M. J. Santofimia, L. Zhao, J. Sietsma. Overview of mechanisms involved during the quenching and partitioning process in steels. in Metallurgical and Materials Transactions A: Physical Metallurgy and Materials Science, 2011, 42, no. 12, 3620-3626, DOI: 10.1007/s11661-011-0706-z.

[8] M.J. Santofimia, L. Zhao, R. Petrov, J. Sietsma. Characterization of the microstructure obtained by the quenching and partitioning process in a low-carbon steel. Mater. Charact., 2008, 59, no. 12, 1758-1764, D0I: 10.1016/ j.matchar.2008.04.004

[9] M. J. Santofimia, L. Zhao, J. Sietsma. Microstructural evolution of a low-carbon steel during application of quenching and partitioning heat treatments after partial austenitization. Metall. Mater. Trans. A Phys. Metall. Mater. Sci.,2009, 40, no. 1, 46-57, DOI: 10.1007/s11661-008-9701-4.

[10] B.C. De Cooman. Structure-properties relationship in TRIP steels containing carbide-free bainite. Curr. Opin. Solid State Mater. Sci.,2004, 8, no. 3-4, 285-303, DOI: 10.1016/j.cossms.2004.10.002.

[11] N. Maheswari, S. G. Chowdhury, K.C. Hari Kumar, S. Sankaran. Influence of alloying elements on the microstructure evolution and mechanical properties in quenched and partitioned steels. Mater. Sci. Eng. A, 2014, 600, 12-20, DOI: 10.1016/j.msea.2014.01.066.

[12] . Kähkönen. Quenching and partitioning response of Carbon-Manganese-Silicon Sheet Steels containing Nickel, Molybdenum, Aluminum, and Copper additions. Master thesis, Faculty and the Board of Trustees of the Colorado School of Mines.

[13] E. J. Seo, L. Cho, B.C. De Cooman. Application of quenching and partitioning processing to medium Mn steel. Metall. Mater. Trans. A Phys. Metall. Mater. Sci., 2015, 46, no. 1, 27-31, DOI: 10.1007/s11661-014-2657-7.

[14] K. Kim , S.J. Lee . Effect of Ni addition on the mechanical behavior of quenching and partitioning (Q\&P) steel. Mater. Sci. Eng. A, 2017, 698, 183-190, DOI: 10.1016/j.msea.2017.05.030.

[15] V. Kurup, C. W. Siyasiya, R.J. Mostert, J. Wicks. The influence of full and partial austenitization temperatures on the quench and partition heat treatment process for an advanced high strength steel. IOP Conf. Ser. Mater. Sci. Eng.,2018, 430, no. 1, DOI: 10.1088/1757-899X/430/1/012045.

[16] E. De Moor, J. Speer, D.K. Matlock, J.H. Kwak, S.B. Lee. Quenching and partitioning of CMnSi steels containing elevated manganese levels. in Steel Research International, 2012, 83, no. 4, 322-327, DOI: 10.1002/srin.201100318.

[17] B. Chen, J. Liang, T. Kang, R. Cao, C. Li, J. Liang, F. Li, Z. Zhao, D. Tang. A study of the optimum quenching temperature of steels with various hot rolling microstructures after cold rolling, quenching and partitioning treatment. Metals (Basel)., 2018, 8, no. 8, DOI: 10.3390/met8080579.

[18] J. Speer, E. De Moor, A. J. Clarke. Critical assessment 7: Quenching and partitioning. Materials Science and Technology (United Kingdom), 2015, 31, no. 1.. 3-9, DOI: 10.1179/1743284714Y.0000000628.

[19] F. HajyAkbary, J. Sietsma, G. Miyamoto, T. Furuhara, M. J. Santofimia. Interaction of carbon partitioning, carbide precipitation and bainite formation during the Q\&P process in a low C steel," Acta Mater., 2016, 104, 72-83, DOI: 10.1016/j.actamat.2015.11.032.

[20] A.J. Clarke, J.G. Speer, M. K. Miller, R.E. Hackenberg, D.V. Edmonds, D.K. Matlock, F.C. Rizzo, K.D. Clarke, E. De Moor. 
Carbon partitioning to austenite from martensite or bainite during the quench and partition (Q\&P) process: A critical assessment. Acta Mater., 2008, 56, no. 1, 16-22, DOI: 10.1016/j.actamat.2007.08.051.

[21] Y. Toji, G. Miyamoto, D. Raabe. Carbon partitioning during quenching and partitioning heat treatment accompanied by carbide precipitation. Acta Mater., 2015, 86, 137-147, DOI: 10.1016/j.actamat.2014.11.049.

[22] Y. Toji, H. Matsuda, M. Herbig, P.P. Choi, D. Raabe. Atomic-scale analysis of carbon partitioning between martensite and austenite by atom probe tomography and correlative transmission electron microscopy. Acta Mater., 2014, 65, 215228, DOI: 10.1016/j.actamat.2013.10.064.

[23] G.A. Thomas, F. Danoix, J.G. Speer, S.W. Thompson, F. Cuvilly. Carbon atom re-distribution during quenching and partitioning. ISIJ Int., 2014, 54, no. 12, 2900-2906, DOI: 10.2355/isij international.54.2900.

[24] E. De Moor, S. Lacroix, A. J. Clarke, J. Penning, J. G. Speer .Effect of retained austenite stabilized via quench and partitioning on the strain hardening of martensitic steels. Metall. Mater. Trans. A Phys. Metall. Mater. Sci.,2008, 39, no. 11, 2586-2595, DOI: 10.1007/s11661-008-9609-z.

[25] S. Ebner, R. Schnitze, C. Suppan, A. Stark, H. Liu, C. Hofer.Characterization of carbides in Q\&P steels using a combination of high-resolution methods. Mater. Charact., 2020, 163, 110242, 2020, DOI: 10.1016/j.matchar.2020.110242.

[26] D.T. Pierce, D.R. Coughlin, D.L. Williamson, J. Kähkönen, A.J. Clarke., J. G. Speer, E. De Moor.Quantitative investigation into the influence of temperature on carbide and austenite evolution during partitioning of a quenched and partitioned steel. Scr. Mater., 2016, 121, 5-9, DOI: 10.1016/j.scriptamat.2016.04.027.

[27] H.N.El-Din, E.A. Showaib, N. Zaafarani, H. Refaiy. Structure-properties relationship in TRIP type bainitic ferrite steel austempered at different temperatures. Int. J. Mech. Mater. Eng., 2017. 12, no. 1, DOI: 10.1186/s40712-017-0071-9.

[28] S. Yan, X. Liu, W. Liu, T. Liang, B. Zhang, Y. Zhao, L. Liu. Comparative study on microstructure and mechanical properties of a C-Mn-Si steel treated by quenching and partitioning (Q\&P) processes after a full and intercritical austenitization. Mater. Sci. Eng. A, 2017, 684, 261-269, DOI: 10.1016/j.msea.2016.12.026.

[29] H.Y. Li, W. Lu X, X.C. Wu, Y. A. Min, X.J. Jin. Bainitic transformation during the two-step quenching and partitioning process in a medium carbon steel containing silicon. Mater. Sci. Eng. A, 2010, 527, no. 23, 6255-6259, D0I: 10.1016/ j.msea.2010.06.045.

PDF automatically generated on 2021-05-20 17:47:57

Article url: https://popups.uliege.be/esaform21/index.php?id=4162

published by ULiège Library in Open Access under the terms and conditions of the CC-BY License (https://creativecommons.org/licenses/by/4.0) 